Revista lus et Praxis, Año 25, № 2, 2019, pp. 151 - 188

ISSN 0717 - 2877

Universidad de Talca - Facultad de Ciencias Jurídicas y Sociales

Aspectos jurídicos sobre la Recarga Artificial de Acuíferos (RAA). Revisión desde el

derecho de aguas chileno, con referencia a España y Australia

Christian Rojas Calderón

Trabajo recibido el 7 de marzo de 2017 y aprobado el 15 de enero de 2019

\title{
Aspectos jurídicos sobre la Recarga Artificial de Acuíferos (RAA). Revisión desde el derecho de aguas chileno, con referencia a España y Australia
}

\author{
LeGal aspects on managed aquifer ReCharge (MAR). SurVey from the \\ Chilean Water law, With ReFerence to Spain and Australia*
}

\section{Christian Rojas CALDerón**}

\section{RESUMEN}

En este trabajo se realiza una descripción fáctica acerca de la Recarga Artificial de Acuíferos en cuanto objeto de estudio, para luego realizar un análisis de dos casos de la regulación dictada especialmente: España y Australia. Luego se expondrá analíticamente la regulación de aguas vigente en Chile aplicable al caso de estudio a nivel legal, reglamentario y de soft law, realizando enseguida un análisis crítico de ello. Finaliza el trabajo con las conclusiones correspondientes.

\section{ABSTRACT}

In this paper the object of study is the Artificial Aquifier Recharge, followed by an thorough analysis of two cases of special regulation: Spain and Australia. Also, there will be an analytical exposition of the current Chilean Regulation of Waters, on different levels, including the legally, regulatory and soft law approach, finishing with a critical analysis and the conclusions.

\section{Palabras Clave}

Recarga artificial de acuíferos, Aguas subterráneas, procedimiento administrativo, derechos de aprovechamiento de aguas provisionales

KEY WORDS

Managed Artificial Recharge, Groundwaters, Administrative Procedure, Provisional Water Use Rights

\footnotetext{
* Proyecto Innova Corfo - FIC Región de Coquimbo 12BPC2-134526 "Evaluación técnica, económica, ambiental y jurídica sobre la Recarga Artificial de Acuíferos. Análisis específico para la provincia de Elqui, región de Coquimbo".

Se agradecen las observaciones y aportes realizados por los profesores Elisa Blanco Lorenzo, Cristián Delpiano Lira, Gonzalo Martínez Merino y Marcos Váquer Caballería.

** Profesor Asistente, Facultad de Derecho de la Universidad Adolfo Ibáñez. Licenciado en Ciencias Jurídicas, U. de Valparaíso; Abogado; Magíster en Ciencia Jurídica y Doctor en Derecho, P. U. Católica de Chile. Investigador asociado del Grupo de Regulación de Riesgos y Sectores estratégicos (Grrise) de la U. de Barcelona. Correo electrónico: christian.rojas@uai.cl; crojascalderon@gmail.com.
} 


\section{Introducción}

En un contexto de un cambio climático que llegó para quedarse, generando claros efectos en la disponibilidad de recursos hídricos, es indispensable que distintas ciencias se unan a objeto de direccionar esfuerzos que tiendan a generar propuestas y respuestas eficaces y congruentes ante una problemática esencial para la vida ordinaria de la población y para la industria en general.

En efecto, alcanzar la seguridad hídrica para todos los usos imaginables constituye en sí un problema fundamental y permanente del desarrollo, de tal manera que debe considerar la variabilidad natural del clima que impulsa el ciclo hidrológico, con las muchas demandas conflictivas de lo que es, esencialmente, un recurso fijo; estas incluyen el aumento de la demanda de agua debido a los mayores requerimientos para las industrias; un mayor y mejor nivel de vida, cambios en las dietas y en los modelos de producción; así como los problemas derivados de la contaminación proveniente de la eliminación de desechos humanos e industriales. De esta manera, al agregar a lo anterior el cambio climático, se complejiza y aumenta expotencialmente la complejidad de los problemas que enfrentan los encargados de la gestión del agua y la sociedad en la lucha por satisfacer las demandas regulares y las nuevas, para alcanzar y mantener una sostenibilidad hídrica que permita dosis previsibles de desarrollo, pues para invertir en la seguridad hídrica que funda el progreso, es necesario invertir en adaptación tecnológica, económica, ambiental y jurídica en todos sus sectores de influencia (tierra, agua, industria, cultura, entre muchos otros) ${ }^{1}$.

Enseguida, resulta pertinente en esta fase introductoria indicar que el concepto y la realidad de las denominadas "nuevas fuentes de agua" se encuentra con una cuestión evidente, que consiste en que, para desalar, transportar o recargar, necesitamos siempre este recurso tan escaso que es el agua; pero no una cualquiera, sino que un agua utilizable o consumible, la que cada vez es más escasa.

Cabe luego tener presente que también animan estas primeras reflexiones la crisis hídrica estructural de Chile y en particular en la Región de Coquimbo -caso o referencia para este estudio-, sin perjuicio de que ella afecta a todo el país; lo que permite afirmar que se requiere de la implementación y desarrollo de soluciones técnicas que no estaban consideradas como viables para nuestra realidad ordinaria, una de las cuales es la Recarga Artificial de Acuíferos ${ }^{2}$.

1 Sadoff y Muller (2010), pp. 17-18.

2 En adelante, RAA. 
En este mismo sentido, la Dirección General de Aguas (DGA) del Ministerio de Obras Públicas, dentro de su política actual, ha desarrollado una línea estratégica denominada "Fomento de nuevas fuentes de agua: infiltración artificial de acuíferos", en cuya virtud se han concretado varios proyectos técnicos de RAA desde 2012, principalmente ${ }^{3}$. A ello se suman -con un interés concurrenteiniciativas regionales en tal sentido, como planes de infraestructura y gestión del recurso hídrico en la Región de Coquimbo, y en especial los asociados al enfrentamiento de la escasez hídrica ${ }^{4}$, y en otras zonas forma parte de temas transversales y condicionantes del desarrollo ${ }^{5}$, pese a que se han detectado condicionantes estructurales ${ }^{6}$.

De todo ello, surge la necesidad de atender muchos temas asociados al conocimiento y gestión sustentable de los recursos hídricos, de manera de visibilizar de forma clara y contundente que actualmente gran parte de los sectores hidrogeológicos de las zonas agrícolas están declarados como zonas de restricción hídrica, por lo que resulta de gran importancia realizar estudios de distinta clase (entre ellos, el de recarga artificial de acuíferos), con el fin de poder determinar las factibilidades técnicas y económicas y cualquier otra -entre ellas, lo jurídico- para ser implementados en cada región. A raíz de ello, se pretenden obtener y entregar orientaciones para los diversos actores asociados a los recursos hídricos, con el objeto de avanzar de una manera más efectiva y eficiente hacia una implementación de RAA.

\footnotetext{
3 De 2012 a 2015, estos fueron: Investigación de recarga artificial de acuíferos en cuencas de río Choapa y Quilimarí, Región de Coquimbo. DGA-AC Ingenieros Consultores. 2012; Mejoramiento de sistemas de aguas subterráneas para utilización de riego en la cuenca del río Copiapó. CNR, Jorquera y Asociados SA. noviembre 2012; Mejoramiento de agua subterránea para riego, Ligua y Petorca. CNR, GCF Ingenieros Ltda. Enero 2013. Es un estudio de prefactibilidad para propuesta de mejoramiento de aguas subterráneas para riego en ambas cuencas; Análisis de alternativas piloto recarga artificial Ligua, Petorca, V Región. CNR, Aqualogy Medioambiente Chile S.A. Agosto 2013; Estudio diagnóstico de zonas potenciales de recarga de acuíferos en las regiones de Arica y Parinacota a la del Maule. CNR, GCF Ingenieros Ltda. Marzo 2013; Estudio recarga artificial de acuíferos en el valle de Aconcagua usando derechos eventuales del fisco. DOH, Ernesto Brown. Enero 2012; Análisis de potencialidad de recarga artificial de acuíferos $1^{\mathrm{a}}$ y $3^{\mathrm{a}}$ sección valle del Aconcagua. DOH, GeoHidrología Consultores. 2012; Estudio e implementación de un plan piloto de recargas artificiales a los acuíferos del valle del Aconcagua. DOH, GeoHidrología Consultores, en ejecución; y Caracterización de la cuenca del Río San José para la implementación de un programa de recarga artificial de acuíferos, proyecto agosto 2012- agosto 2014. INH Gobierno Regional de Arica y Parinacota.

${ }^{4}$ Gobierno Regional de Coquimbo (2015), pp. 25-57.

${ }^{5}$ Gobierno Regional de Valparaíso (2015), p. 71.

${ }^{6}$ El Mercurio (2018).

De todas maneras, conforme un estudio encargado por la Comisión Nacional de Riego a la consultora GCF Ingenieros en 2013, de dieciocho cuencas analizadas desde las regiones de Arica y Parinacota hasta la del Maule, solo ocho tienen potencial de recarga de acuíferos.
} 


\section{Consideraciones fácticas sobre la RAA}

\subsection{Contexto general de la RAA y definiciones}

La recarga artificial de acuíferos (RAA, o también $A R$ o $M A R^{7}$ ), sobre todo a partir de avances significativos registrados en los aspectos técnicos, ha sido reconocida en los últimos años como una herramienta de gestión hídrica y económica de gran efectividad en el ámbito de las grandes obras hidráulicas, en miras a la gestión integral de los recursos hídricos (GIRH).

A consecuencia de su desarrollo, se ha identificado que la tecnología aplicable para conseguir la recarga de acuíferos es compleja y su elección depende de varios factores, a saber: el nivel y tipo de acuífero; calidad de las aguas subterráneas del acuífero que se quiere recargar; el tipo y calidad del agua que se quiere utilizar para la recarga; las características y tipo de suelo donde se encuentra el acuífero, y proximidad a la superficie del terreno, así como su extensión.

Luego, para seguir avanzando, conviene señalar que se ha definido descriptivamente a la RAA como "el desarrollo de obras que permiten la recarga forzada de aguas superficiales a las napas subterráneas, en aquellos lugares con aptitud para recibir dicha recarga y poder extraerlas con posterioridad, utilizando para ello la capacidad e almacenamiento que tienen los acuíferos ${ }^{\prime \prime}$. Otra, que se considera mejor y se recoge en el Libro Blanco del Agua en España, define la RAA como "un conjunto de técnicas que permiten, mediante intervención programada e introducción directa, inducida o estimulada de agua en un acuífero, incrementar el grado de garantía y disponibilidad de los recursos hídricos, y actuar sobre su calidad"9.

A partir de ello, es posible sostener que existen diversos sistemas de recarga de acuíferos, pudiendo distinguir los métodos de introducción directa, inducida ${ }^{10}$ o estimulada. También puede agregarse como tipología aquella que, pensando en los sistemas de recarga artificial de acuíferos, los divide a su vez en dos tipos: i) superficiales, como serpenteos, represas, vasos permeables, balsas o fosas, y ii) en profundidad, como sondeos de inyección, simas y dolinas, drenes, galerías y zanjas $^{11}$. Finalmente, dependiendo del tipo de agua que se introduce en los acuíferos, podemos distinguir entre recarga de agua superficial, subterránea, regenerada o desalada.

\footnotetext{
7 Por Artificial Recarge (AR) o también Managed Artificial Recharge (MAR), acrónimos más utilizados en los foros internacionales y citas.

${ }^{8}$ Gobierno de Chile (2012), p. 34.

${ }^{9}$ Ministerio de Agricultura, Alimentación y Medioambiente (s/d).

${ }^{10}$ La recarga inducida consiste en provocar la filtración natural que tiene lugar desde ríos, lagos o embalses, mediante pozos de bombeo situados relativamente cerca de dichas masas de agua.
}

11 SASTRE (2009), p. 280. 
Esta resulta ser una actividad de primer orden en varios países del mundo, tales como Alemania, Holanda, EE.UU., Australia e Israe ${ }^{12}$. Precisamente en algunos países de Europa es en donde esta técnica se emplea más frecuentemente, como Alemania y Holanda; en efecto, en la ciudad alemana de Chemnitz, a fines del siglo XIX se realizó la primera recarga artificial. Hoy la ciudad de Düsseldorf se abastece en un $100 \%$ con aguas obtenidas mediante técnicas de recarga de acuíferos, Berlín depende de este tipo de aguas en un $75 \%$, y Ámsterdam se abastece en un $65 \%$ con agua proveniente de la recarga.

La misma técnica está siendo utilizada desde hace tiempo en los Estados Unidos, en concreto en el Metropolitan Water District of Southern California, y por la Arizona Water Banking Authority ${ }^{13}$.

Por su lado, en Australia a través de la generación de un marco regulatorio adecuado y claro se han creado incentivos para la RAA, en virtud de reconocimiento de un título de uso por la autoridad estatal sobre el agua infiltrada; trabajando en la información, a través de la generación de mapas indicativos de acuíferos con aptitud para recarga; realización de proyectos piloto con fondos estatales, cuyos resultados se encuentran disponibles públicamente. Al mismo tiempo se han propuesto claros lineamientos para la protección de la salud y el medioambiente, a través de una estrategia nacional de calidad de aguas, que ha considerado la RAA en la planificación y gestión de los recursos hídricos, y se ha incentivado la participación activa de la comunidad a través de un intenso traspaso de información, con consulta pública obligatoria.

Finalmente, en el caso de España existen algunas experiencias de recarga de acuíferos, entre las que es posible mencionar los proyectos realizados en acuíferos declarados sobreexplotados. Por ejemplo, en la cuenca alta del Guadiana, introduciendo aguas al acuífero de la Mancha Occidental mediante sondeos ubicados en las inmediaciones de Alcázar de San Juan en la Ciudad Real; se ha llevado a cabo la recuperación del acuífero del río Besòs mediante recarga artificial del río Llobregat -en el área de Cataluña-, para asegurar el suministro de agua potable en los períodos que, bien por escasez de aguas superficiales o por deficiente calidad de las mismas, no es posible satisfacer totalmente la demanda con agua de origen superficial ${ }^{14}$, e instalando dispositivos en la zona correspondiente al Acuífero Los Arenales, que pasa por las provincias de Valladolid, Segovia y Ávila. Incluso, recientemente -dada la persistente sequía-, se han proyectado

\footnotetext{
12 Fernández (2010), pp. 31-32.

13 SASTRE (2009), p. 279.

14 SASTRE (2009), p. 279.
} 
pruebas piloto para recargar acuíferos con agua depurada, derivada de los sistemas de alcantarillado ${ }^{15}$.

Hasta ahora, este es el contexto general.

En el caso particular de la comunidad autónoma de Cataluña, la recarga artificial de acuíferos se realiza por dispositivos de infiltración y sondeos en el aluvial de los ríos; en Segovia, la recarga se hace mediante canales y zanjas; en Madrid y Castilla-La Mancha, las experiencias más notables se han realizado mediante sondeos profundos; en Andalucía Central hay sistemas de acequias (careos), drenajes de minas y sondeos, y en Andalucía Occidental predominan los pozos y balsas como dispositivos de infiltración inducida.

Luego, existe consenso de acuerdo a la experiencia internacional -recogido, por ejemplo, por la National Water Commision de Australia- en que, para implementar iniciativas de RAA, es necesario abordar un proceso que involucra al menos tres etapas: a) desarrollo de estudios experimentales; b) demostración de proyectos de RAA, y, por último, c) la implementación de las iniciativas.

\subsection{Elementos y consideraciones básicas del caso en estudio: La cuenca del río Elqui}

Dado lo explicado, los análisis que pueden realizarse siempre deben ser localizados, estimándose que la mejor o más adecuada área de estudio es la cuenca hidrográfica.

La consecuencia de lo dicho es, en primer lugar, la necesaria caracterización fáctica de lo que se considera el área estudio, lo cual implica incorporar los siguientes ítemes ${ }^{16}$ : a) desarrollo de una cartografía hidrogeológica que permita una evaluación inicial del potencial de la RAA; b) análisis de los costos y beneficios de las alternativas de la RAA donde se pueda establecer comparación con otro tipo de soluciones; c) recomendaciones para una reglamentación que permita ejecutar los RAA; d) hacer públicamente accesible la información sobre RAA, para permitir el conocimiento de todas las instancias asociadas al manejo de los recursos hídricos, y e) establecimiento de recomendaciones para arreglos institucionales que puedan desarrollar las inversiones requeridas.

A partir de lo anterior se puede afirmar, en general, que el sector de estudio correspondiente, la cuenca del Elqui, ubicado en la provincia del Elqui en la Región de Coquimbo, presenta importantes desafíos en los requerimientos de recursos hídricos.

15 Fernández-Escalante y San Sebastián (2017), pp. 766-768.

${ }^{16}$ Igualmente, se toman como referencia las indicaciones realizadas por la National Water Commission australiana (NWC). 
En efecto, por un lado en el área se observa una creciente demanda de recursos hídricos, dado el importante crecimiento de la actividad agrícola, minera y de agua potable, demanda que crecerá en los próximos 20 años en un $30 \%$ aproximadamente ${ }^{17}$, siendo el sector minero el mayor aumento, con un crecimiento de un 45 $\%$ en los próximos 10 años ${ }^{18}, y$, por otro, se observa para el futuro una disminución de las fuentes tradicionales de recursos hídricos, producto del cambio climático, lo que ha provocado en los últimos 60 años una disminución del $20 \%$ de las precipitaciones en la ciudad de La Serena. También se prevé que, a consecuencia de esta condición climática, las reservas de nieve disminuirán fuertemente, ya que se producirá un aumento de las temperaturas en la cordillera, lo que provocará un derretimiento más acelerado de las reservas.

Ante este escenario, es probable que se acrecienten los conflictos entre los diversos actores asociados al recurso hídrico si es que no se aumenta de manera importante la eficiencia del uso del recurso hídrico y, al mismo tiempo, si no se desarrollan fuentes no tradicionales de agua a través de la desalinización, el uso de aguas tratadas reutilizables o se desarrollan las condiciones para la RAA.

Bajo estas consideraciones, resulta adecuado explicar que la Región de Coquimbo surte sus necesidades de recursos hídricos con fuentes tanto superficiales como subterráneas, las que son originadas principalmente de tres importantes cuencas: Elqui, Limarí y Choapa. Todas ellas nacen en la cordillera de Los Andes y desembocan en el mar, y su alimentación es pluvio-nival. A ellas les siguen, en orden de importancia, cuencas costeras, como la de Los Choros, Quilimarí entre otras, cuya alimentación es pluvial. Ahora bien, en una caracterización general de la región, en lo que respecta a la provincia y cuenca hidrográfica del Elqui, se encuentran tres acuíferos: Cubrelón-Lagunillas, quebrada Los Choros y Elqui.

Con relación al estado actual de los recursos hídricos subterráneos de la región, al año 2005 (Resolución Exenta DGA № 2.045, 29 de diciembre de 2005) se habían otorgado 22.472 litros por segundo de derechos subterráneos permanentes, de los cuales 14.677 (65\%) pertenecen a la cuenca de Elqui, siendo por ende el área más importante a nivel regional en esta materia.

Particularmente, en lo que respecta al sector acuífero de Elqui, sus aguas son aprovechadas principalmente en el regadío del valle del Elqui; la minería y para consumo humano de las ciudades de La Serena, Coquimbo y Vicuña, además del casi centenar de pueblos o poblados en dicha provincia, y dentro de esta cuenca se encuentran tres importantes sectores acuíferos denominados Elqui Alto, Elqui Medio, Elqui Bajo, y Santa Gracia.

17 Dirección General de Aguas (2007), pp. 51-54.

${ }^{18}$ Comisión Chilena del Cobre-Cochilco (2009), p. 23. 
En cuanto al acuífero Los Choros, este tiene un área total de 42.678 hectáreas y no tiene su cabecera en la cordillera de Los Andes, sino que en la cordillera de la Punilla, donde las cumbres más altas no superan los 4.000 metros sobre el nivel del mar, lo que limita el aporte de aguas producto del derretimiento de nieves. Debido a lo anterior, la quebrada de Los Choros no posee un régimen de escurrimientos continuo a lo largo del año, y las precipitaciones normales infiltran rápidamente en el relleno sedimentario, generalmente en el curso superior y medio de la quebrada denominado río Los Choros; en esta área son relevantes los acuíferos Los Choros Alto y Bajo, Tres Cruces, entre otros.

Finalmente, al sur del río Elqui se encuentra el acuífero Culebrón-Lagunillas, el cual presenta una superficie de 784 kilómetros cuadrados, que se divide en tres sectores acuíferos: Peñuelas, Culebrón y Lagunillas, siendo Culebrón uno de los acuíferos más relevantes de la región, donde se encuentran alrededor de 5.000 hectáreas de cultivo y donde existe también una importante extracción de recursos para la actividad minera y sanitaria (al concentrarse acá los núcleos urbanos).

Luego, al realizar un análisis de la demanda otorgada por la Dirección General de Aguas (DGA, en adelante) de derechos subterráneos permanentes y la oferta de recursos hídricos, es posible establecer que existen acuíferos en la cuenca de Elqui donde la oferta de recursos hídricos subterráneos a largo plazo no alcanza a cubrir la demanda otorgada, corregida por su factor de uso previsible $(0,2$ en agricultura y 0,75 en agua potable y minería). Si no se hiciera esta corrección, se acrecentaría aún más el déficit de recursos.

Ante la situación anteriormente descrita, la DGA ha procedido a establecer áreas de restricción en diversos acuíferos de la provincia, con el objeto de no provocar mayores desbalances y entregando posteriormente solo derechos provisionales en estas áreas. Al mes de diciembre del año 2018, en la provincia de Elqui de la Región de Coquimbo existían 10 sectores hidrogeológicos, definidos como Áreas de Restricción para nuevas extracciones de aguas subterráneas, los que se detallan a continuación ${ }^{19}$ :

i) Comuna de La Higuera, acuífero Los Choros: sectores hidrogeológicos de Tres Cruces, Punta Colorada y Los Choros Alto.

ii) Comuna de La Serena, acuífero Elqui: sectores hidrogeológicos de Elqui Alto, Elqui Medio, Elqui Bajo y Serena Norte.

iii) Comuna de Coquimbo, acuífero Culebrón: sectores hidrogeológicos de Peñuelas, Culebrón y Lagunillas.

19 Dirección General de Aguas (en línea), "Mapas interactivos". 
Los desbalances anteriormente comentados han traído una disminución de los niveles piezométricos y, como sostiene la DGA, “(...) en el acuífero Culebrón se tiene una marcada tendencia a la baja a partir del año 1994" 20 .

Conforme lo descrito, y las tendencias anteriormente indicadas, es posible que se incrementen por variadas razones: en primer término, producto del cambio climático se espera que existan lluvias más intensas en tiempos más cortos, lo que resulta en una menor recarga natural de los acuíferos, debido a que la recarga de aguas subterráneas depende del área y tiempo de infiltración; en segundo lugar, el efecto de urbanización sobre zonas de recarga pone en peligro la calidad y cantidad de agua subterránea; en tercer término, se suma a lo anterior -lo que dificulta la recarga- el problema de erosión actual, que lidera a nivel nacional la Región de Coquimbo con 84 \% de sus suelos, lo que ciertamente reduce su capacidad para retener agua y recargar los acuíferos que permiten el abastecimiento; finalmente, la recarga proveniente del "derrame" natural derivado del riego superficial ha tendido y seguirá tendiendo a disminuir, ya que por la intensificación en el uso de tecnologías altamente eficientes en el riego (como el goteo) y el revestimiento de canales -unido al aumento de superficie regada-, disminuyen ciertamente las posibilidades de recarga que natural o indirectamente se producían.

A partir de las condiciones anteriormente señaladas, el Plan regional de infraestructura y gestión del recurso hídrico al 2021 de la Región de Coquimbo propuso "realizar estudios de recarga artificial de acuífero, con el fin de poder determinar las factibilidades técnicas y económicas para ser implementados en la región", y el Plan estratégico contra la escasez hídrica 2015-2025 también propuso, entre varias medidas, a lo menos un proyecto de recarga de acuíferos.

\subsection{Las técnicas de recarga de acuíferos aplicables}

Para avanzar, conviene tener presente que existen diversos métodos para producir recargas artificiales: almacenamiento de aguas en embalses construidos sobre áreas de suelo permeable; derivación del caudal de los ríos hacia áreas de dispersión, que son superficies de mayor permeabilidad; excavación de fosas de percolación hasta penetrar zonas más permeables; bombeo de agua dentro del acuífero por medio de pozos de inyección, y construcción de pozos adyacentes a un río para inducir la percolación a partir del mismo. Asimismo, existen combinaciones de estos métodos y diversas variaciones, las cuales se evalúan conforme a las características geológicas y físicas.

20 Dirección General de Aguas (2012), p. 29. 
Luego, los acuíferos más adecuados para la recarga artificial son aquellos que tienen un valor pequeño en la relación de transmisibilidad-conductividad, que son los que absorben grandes cantidades de agua y nos la liberan de prisa, favoreciendo su sostenibilidad. Teóricamente esto significa que la conductividad hidráulica vertical es significativa, mientras que la horizontal es moderada; de lo que se sigue que, para poder retener estos recursos es necesario realizar una gestión hídrica planificada, en la que aguas superficiales ocasionales, sobrantes o especialmente destinadas, se almacenan en los acuíferos para incrementar los recursos hídricos y para mantener o constituir una reserva disponible para situaciones de escasez estacional ${ }^{21}$.

En fin, sin perjuicio de que este estudio centra sus análisis en la provincia de Elqui en la Región de Coquimbo, es posible extrapolar sus resultados a todas las regiones con características hídricas similares en Chile.

En lo que sigue, se analizarán dos ejemplos paradigmáticos: España y Australia; se darán algunas consideraciones sobre el régimen jurídico de la RAA -O, más bien, la falta de este en nuestro país-y se señalarán algunas condiciones que se consideran como imprescindibles para el desarrollo adecuado de esta clase de iniciativas.

\section{Análisis de dos paradigmas: España y Australia}

\subsection{La RAA en España ${ }^{22}$}

\subsubsection{Las responsabilidades en la gestión del agua}

Como se señaló anteriormente, en España se han desarrollado varias iniciativas que permiten sostener un modelo de recarga, dentro del marco general de gestión integrada de recursos hídricos, con un modelo complejo y completo de

\footnotetext{
21 Sobre esto, MuriLlo (2002), pp. 121-122.

En la determinación de la potencial RAA en el área en observación es fundamental tener presente los estudios hidrogeológicos básicos de las diversas cuencas -los que conforman el marco general, sin perjuicio del área específica de estudio-; en este sentido, un avance importante posee la región, ya que cuenta con diversos estudios, tanto públicos como privados, que abarcan la gran mayoría de los acuíferos: a) Departamento de Administración de Recursos Hídricos. DGA (2003), Evaluación de los recursos hídricos subterráneos de la cuenca del Río Elqui, IV Región. S.D.T. № 161 Santiago.

b) Informe técnico DGA (2004), Modelo de simulación Quebrada Los Choros Evaluación de los Recursos Hídricos en la Quebrada Los Choros, IV Región de Coquimbo.

c) TECK-CDA-INGEOREC (2011), Hidrología y modelo numérico de la cuenca del Estero Culebrón. Informe final.

d) TECK-CDA-Hidrogeología (2010), Modelación modflow de acuífero del Valle de Elqui, sector Bajo Puclaro. Informe.

e) DGA (2004), Aplicación del modelo hidrogeológico Valle Pan de Azúcar. STD № 176.

22 Se toma como base a SASTRE (2009), pp. 280-284.
} 
aguas. Este surge como un mecanismo más para paliar la gran diferencia hídrica existente entre distintas zonas de la península, en especial las áreas deficitarias ubicadas en el sur y sobre todo el suroeste, con respecto al resto del país.

Al efecto, se cuenta con un sistema basado en la consideración de las cuencas hidrográficas como base de la organización en torno a la gestión de los recursos hídricos, a partir de las cuales se construye toda su institucionalidad administrativa con respecto al aprovechamiento del agua, lo que se concreta en las "Confederaciones Hidrográficas", que son organismos autónomos, aunque dependientes del Ministerio de Medio Ambiente, que gozan de amplia autonomía y desempeñan las esenciales actividades de gestión de las aguas en cuenca ${ }^{23}$. Su estructura institucional se basa en la existencia de órganos de gobierno -junta de gobierno y presidente-, órganos de gestión -asamblea de usuarios, comisión de desembalse, juntas de explotación y juntas de obras-, y un órgano de participación y planificación -Consejo de Agua de la Demarcación-.

Sus funciones más relevantes se sintetizan en la elaboración del plan hidrológico de cuenca, así como su seguimiento y revisión; la administración y control del dominio público hidráulico, incluyendo el otorgamiento de autorizaciones y concesiones; la administración y control de los aprovechamientos de interés general o que afecten a más de una comunidad autónoma; el proyecto, construcción y explotación de las obras realizadas con cargo a los fondos propios del organismo; las que le sean encomendadas por el Estado; las que deriven de los convenios con las Comunidades Autónomas, Corporaciones Locales y entidades públicas o privadas, y los suscritos con los particulares. Hay que agregar que, junto a esta organización administrativa estatal, existe también una organización administrativa de las comunidades autónomas ${ }^{24}$ que se ha concretado en "agencias", como la Agencia Catalana del Agua y la Agencia Vasca del Agua; asimismo, también existen muchos otros organismos con competencia sectorial, como el Instituto del Agua de Aragón o el Ente Público de Agua (EPA) de Murcia.

En fin, al lado de estos se encuentran las comunidades de usuarios, colaboradoras en la gestión del dominio público hidráulico y con claras potestades públicas ${ }^{25}$.

\footnotetext{
23 EMBID (2008), pp. 48-51.

${ }^{24}$ Concentrándose las disputas hoy existentes en España en esta materia, en la definición del ámbito de competencias de ellas de frente a la Administración central.

Sobre ello, EmBID (2009), pp. 247-285.

${ }^{25}$ En torno a su naturaleza jurídica existe consenso de tratarse de un caso de corporaciones de derecho público.
} 


\subsubsection{Sistematización del régimen jurídico a nivel comunitario ${ }^{26}$}

Dentro de la normativa comunitaria se contienen algunas especificaciones sobre la recarga artificial de acuíferos, entre las que podemos señalar las siguientes:

a) Directiva 80/68/CE, de 17 de diciembre de 1979, relativa a la protección de las aguas subterráneas contra la contaminación causada por determinadas sustancias (DOCE núm. L20, de 26 de enero de 1980), derogada por la Directiva 2000/60/CE, de 23 octubre, que establece un marco comunitario de actuación en el ámbito de la política de aguas.

En concreto, el artículo $6^{\circ}$ de la citada directiva menciona específicamente la recarga artificial de acuíferos en los siguientes términos:

"Artículo 6 $6^{\circ}$ - No obstante lo dispuesto en los artículos $4^{\circ}$ y $5^{\circ}$, las recargas artificiales de las aguas subterráneas para la gestión pública de las mismas, estarán sometidas a una autorización particular, que los Estados miembros concederán caso por caso. Dicha autorización sólo se concederá si no hubiere riesgo de contaminación de las aguas subterráneas".

Se agrega a estos efectos el artículo 13, que dispone lo siguiente:

"Artículo 13.- Las autoridades competentes de los Estados miembros controlarán el cumplimiento de las condiciones impuestas por las autorizaciones así como la incidencia de los vertidos en las aguas subterráneas".

De esta directiva se desprende que la recarga artificial de acuíferos está sometida a una autorización particular de la autoridad administrativa competente en la materia en cada uno de los respectivos Estados miembros. Dicha autoridad deberá controlar que se cumplan las condiciones impuestas en el título habilitante.

b) Directiva del Consejo 2006/118/CE, de 12 de diciembre de 2006, relativa a la protección de las aguas subterráneas contra la contaminación y el deterioro.

También en el artículo $6^{\circ}$, ahora de esta directiva, se establecen una serie de medidas para prevenir o limitar las entradas contaminantes en las aguas subterráneas. No obstante, se permite a los Estados miembros eximirse de tomar tales medidas cuando aquello sea resultado de una recarga artificial, conforme específicamente lo permite el artículo 6.3.d).

26 SAStRe (2009), pp. 280-281. 
c) Directiva 2011/92/UE del Parlamento Europeo y del Consejo de 13 de diciembre de 2011, relativa a la evaluación de las repercusiones de determinados proyectos públicos y privados sobre el medio ambiente (DO L 026, 28.1.2012). Modificada por Directiva 2014/52/UE del Parlamento Europeo y del Consejo, de 16 de abril de 2014, por la que se modifica la Directiva 2011/92/UE ${ }^{27}$.

La directiva comprende entre los proyectos sometidos a evaluación ambiental la recarga artificial de acuíferos, siempre que el volumen anual de agua aportada sea igual o superior a 10 millones de metros cúbicos.

En efecto, en el Anexo I se incluyen:

"11. Proyectos para la extracción de aguas subterráneas o la recarga artificial de acuíferos si el volumen anual de agua extraída o aportada es igual o superior a 10 millones de metros cúbicos".

Los proyectos de recarga artificial de acuíferos de menor volumen se encuentran comprendidos en el Anexo II:

"10. Proyectos de infraestructura [...]

I) Proyectos de extracción de aguas subterráneas y de recarga artificial de acuíferos no incluidos en el Anexo I".

En estos proyectos, es la autoridad competente la que decide si se somete a evaluación: a) mediante un estudio caso por caso, o b) mediante umbrales o criterios establecidos por el Estado miembro.

d) Directiva 2000/60/CE del Parlamento Europeo y del Consejo de 23 de octubre de 2000, por la que se establece un marco comunitario de actuación en el ámbito de la política de aguas (en adelante, Directiva Marco del Agua) (DOCE núm. L 327, de 22 de diciembre de 2000).

El artículo 11 de la Directiva Marco del Agua, al regular el "Programa de medidas", comprende -dentro de las mismas- las medidas de control de la recarga artificial de acuíferos en los siguientes términos:

"3. Las medidas básicas son los requisitos mínimos que deberán cumplirse y consistirán en:

[...] f) Medidas de control, con inclusión de un requisito de autorización previa, de la recarga artificial o el aumento de masas de agua subterránea. El agua que se utilice podrá obtenerse de cualquier agua superficial o subterránea, siempre que el uso de la fuente no comprometa la consecución de los objetivos medioambientales establecidos para la

\footnotetext{
${ }^{27}$ La anterior Directiva EIA de 1985 fue modificada en 1997 en varias ocasiones, hasta ser derogada y sustituida por la Directiva 2011/92/UE, a su vez modificada en 2014.
} 
fuente o la masa de agua recargada o aumentada. Dichos controles se revisarán periódicamente y, cuando proceda, se actualizarán".

Como puede verse, en este precepto se entiende la recarga artificial como "masa de agua recargada o aumentada", lo que requiere autorización previa.

Dentro del Anexo II, en la sección sobre "Aguas subterráneas", se establece en el apartado 1.2.1. que los Estados miembros llevarán a cabo una caracterización inicial de todas las masas de agua subterránea, para poder evaluar su utilización y la medida en que dichas aguas podrían dejar de ajustarse a los objetivos para cada masa de agua subterránea a que se refiere el artículo $4^{\circ}$. En el análisis que sigue se indicará, entre otros aspectos, la recarga artificial de agua.

Finalmente, se realizará una caracterización adicional que incluirá: las tasas de recarga, conforme el Anexo II, punto 2.3.e); la composición química de las aguas introducidas en la recarga del acuífero de acuerdo al Anexo II, punto 2.3.f), y el uso del suelo en la zona o zonas de recarga natural a partir de las cuales la masa de agua subterránea recibe su alimentación, incluidas las entradas contaminantes y las alteraciones antropogénicas de las características de la recarga natural (como por ejemplo la desviación de las aguas pluviales y de la escorrentía mediante la impermeabilización del suelo, la alimentación artificial, el embalsado o el drenaje), en virtud de lo establecido en el Anexo II, punto 2.3.g).

\subsubsection{Regulación española ${ }^{28}$}

En este caso, la legislación española siempre ha sido muy vanguardista -además de compleja-, por lo que es posible identificar los siguientes niveles:

a) En la legislación de aguas estatal (Real Decreto Legislativo $\mathbf{N}^{\mathbf{0}}$ 1/2001, de 20 julio, que aprueba el Texto Refundido de la Ley de Aguas y reglamentos que la desarrollan).

Para esta parte distinguiremos entre títulos habilitantes, planificación hidrológica y obras de infraestructura para recarga.

\section{(a.a.) Títulos habilitantes}

El agua destinada a la RAA, al formar parte del dominio público hidráulico, requiere de la obtención de los siguientes títulos:

i. Si la recarga se realiza por particulares, al ser un uso privativo de las aguas requiere de concesión administrativa, conforme el artículo 59 del Real Decreto

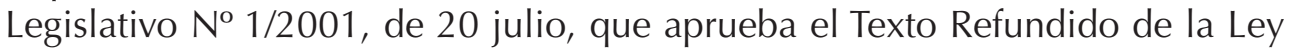
de Aguas (en adelante, TRLA).

28 SAStRe (2009), pp. 281-284. 
ii. Por el contrario, si la recarga se realiza dentro de las actividades de investigación de la Administración Pública o dentro de los objetivos marcados en la planificación hidrológica, solamente será necesaria una autorización especial extendida a favor de la Administración de que se trate, sin perjuicio de terceros (art.59.4 del TRLA)

Si la recarga se realiza dentro del perímetro de protección del acuífero, requiere autorización del organismo de cuenca, al suponer la realización de obras o actividades que pudieran afectar al mismo, en virtud de lo dispuesto en el artículo 173.1 del Reglamento del Dominio Público hidráulico.

\section{(a.b.) Planificación hidrológica}

La RAA, como medio de gestión de las aguas, debe ser recogida en los planes hidrológicos de cuenca.

En concreto, dentro del contenido de los planes hidrológicos de cuenca, en el capítulo de "Programas de Medidas", se incluirán conforme el artículo 42.1.g) subapartado $k^{\prime}$ ) del TRLA:

"Las directrices para recarga y protección de los acuíferos".

Respecto a las directrices para la RAA, el artículo 53 del Reglamento de Planificación Hidrológica (aprobado por Real Decreto No 907/2007, de 6 de julio) establece lo siguiente:

"1. El plan hidrológico recogerá, cuando existan, las áreas de recarga artificial de masas de agua subterránea, para las que se detallará el objetivo de la recarga, así como la procedencia, cuantía y calidad de los recursos aplicados, incluyendo la autorización que permite la recarga. Las sucesivas áreas de recarga que vayan determinándose se incorporarán al Plan a medida que se autoricen.

2. Los recursos aplicados para la recarga artificial podrán obtenerse de cualquier agua superficial, subterránea, regenerada o desalada, siempre que el uso de la fuente no comprometa la consecución de los objetivos medioambientales establecidos para la fuente o la masa de agua recargada ni pueda generar situaciones de riesgo para la salud pública".

Este precepto deja claro que en los planes hidrológicos de cuenca habrá que detallar el objetivo de la recarga, así como la procedencia, cuantía y calidad de los recursos destinados a la recarga artificial de acuíferos. Los recursos empleados para la recarga podrán proceder de agua superficial, subterránea, regenerada o desalada.

Por "agua regenerada" se entiende "aguas residuales depuradas que, en su caso, han sido sometidas a un tratamiento adicional o complementario que permite adecuar su calidad al uso que se destinan", de acuerdo a lo establecido 
en el artículo $2^{\circ}$.c) del Real Decreto $N^{\circ} 1.620 / 2007$, de 7 de diciembre, por el que se fija el régimen jurídico de la reutilización de las aguas depuradas.

Las aguas regeneradas que se destinen a la recarga artificial de acuíferos están sometidas a unos criterios de calidad en función de si la misma se realiza mediante percolación localizada, a través del terreno o por inyección directa en virtud del Anexo 1.A -Criterios de calidad para la reutilización de las aguas según sus usos- del Real Decreto $N^{\circ} 1.620 / 2007$, de 7 de diciembre: vid. "5. Usos ambientales".

\section{(a.c.) Obras de infraestructura de RAA}

Dentro de la definición de obra hidráulica, el artículo 122 del TRLA también comprende "las que tengan por objeto la recarga artificial de acuíferos". Dichas obras pueden ser de titularidad pública o privada.

La iniciativa para su declaración como obra hidráulica de interés general corresponde al Ministerio de Medio Ambiente, Medio Rural y Marino, al resto de los departamentos ministeriales de la Administración General del Estado, a las comunidades autónomas, a entidades locales, y a las comunidades de usuarios u organizaciones representativas de los mismos (art. 131 del TRLA).

A título de ejemplo de recarga artificial de acuíferos de interés general, podemos citar la recarga de la Cubeta de Santiuste de San Juan Bautista (Segovia).

Finalmente, la Ley $N^{\circ}$ 10/2001, de 5 de julio, del Plan Hidrológico Nacional, recoge en su Anexo II (Listado de inversiones) un conjunto de actuaciones destinadas a mejorar el uso y conservación del recurso, dentro de las cuales se encuentran las siguientes actuaciones de RAA:

"[...] La Infraestructura de refuerzo de recarga artificial en el Alto Guadiana.

[...] Infraestructura de refuerzo de recarga artificial en el Júcar".

Estas obras, al estar incluidas en el Anexo II, se declaran de interés general, por lo que llevan implícita la declaración de utilidad pública, y la necesidad de ocupación de los bienes y adquisición de derechos, a los fines de expropiación forzosa y ocupación temporal (art. 130 del TRLA). Tampoco están sujetas a licencia municipal ni a cualquier acto de control preventivo municipal (art. 127 del TRLA).

Por último, si las infraestructuras necesarias para la recarga artificial están situadas o invaden los cauces de los ríos, de su zona de servidumbre (5 metros) o de policía (100 metros) requieren autorización del organismo de cuenca (arts. 70 y 78 del RDPH).

\section{b) En la legislación ambiental española}

Sobre este aspecto, en el Real Decreto Legislativo $N^{\circ} 1 / 2008$, de 11 de enero, entre los proyectos que se encuentran sometidos a Evaluación de Impacto Ambiental se encuentran los de RAA si el volumen anual de agua aportada es igual o superior a 10 millones de metros cúbicos, conforme al Anexo I. En 
el supuesto de que el volumen de agua a recargar sea superior a 1 millón de metros cúbicos, pero inferior a 10 millones de metros cúbicos, únicamente deberá someterse a una evaluación de impacto ambiental cuando así lo decida el órgano ambiental en cada caso [artículo 3.2.a) y Anexo II, Grupo 8, apartado a), del Real Decreto Legislativo No 1/2008].

Conviene dejar en claro que los impactos ambientales son inherentes a la presencia de instalaciones necesarias para la recarga, tanto principales (tuberías, desagües, válvulas de compuerta, etc.) como accesorias (vallas de seguridad, caminos de servicio, pasos elevados, etc.).

Estos impactos ambientales tienen lugar durante la construcción de las instalaciones: acondicionamiento del terreno, realización de nivelaciones, desmontes y terraplenes, movimientos de maquinaria pesada, etc., así como durante la etapa de aprovechamiento de los mismos (trabajos de explotación).

\section{c) En los planes hidrológicos de cuenca actuales}

En los planes hidrológicos de cuenca aprobados por Real Decreto $N^{0} 1.664 / 1998$, de 24 de julio, con acuíferos declarados, provisional o definitivamente sobreexplotados, es donde con mayor concreción se describe la RAA.

En concreto, en el Plan Hidrológico de la Cuenca Sur se distingue entre dos tipos de recarga: i) en función de si el origen de los recursos es en presas para laminación de avenidas, o ii) por aguas residuales depuradas. Así, para la recarga del acuífero de Campos de Dalías (Almería), se previó un sistema mixto con aguas depuradas y con las procedentes de la presa de Beninar en períodos de avenida y del acuífero que recoge las filtraciones de la misma (art. 29). En el Plan Hidrológico del Ebro se incluye una lista de unidades hidrogeológicas en las que se estudiará si son susceptibles de ser recargadas artificialmente (art. 113). En el Plan Hidrológico del Júcar, pese a tener dos acuíferos declarados provisionalmente sobreexplotados (Sierra de Crevillente y Jumilla-Villena), no se hace referencia a esta técnica.

En el Plan Hidrológico de la Cuenca del Duero se contemplaban dos directrices, en las que literalmente se indicaba la necesidad de "estudiar y establecer las normas para la recarga y protección de acuíferos, la declaración en su caso de acuíferos sobreexplotados y la posible recarga artificial de determinadas áreas", para lo cual se señalaba la intención de "catalogar las infraestructuras básicas requeridas por el Plan para la recarga artificial de acuíferos".

\section{d) Instrucción de planificación hidrológica}

En la Orden ARM/2656/2008, de 10 de septiembre, por la que se aprobó la Instrucción de Planificación Hidrológica en las cuencas intercomunitarias, se manifiesta que se identificarán en los futuros planes las siguientes recargas artificiales (apartado 3.2.3.4.):

a) Vertidos a las aguas subterráneas para recarga artificial de los acuíferos. 
b) Retornos de agua subterránea a la masa de agua de la cual fue extraída (por ejemplo, para lavado de áridos).

c) Recarga con aguas de achique de minas.

d) Otras recargas significativas.

Para cada recarga se señalará su situación indicando las coordenadas.

Luego, para cada recarga identificada se indicarán, cuando sea posible, los recursos de agua disponibles para la RAA, señalando su origen, su régimen temporal de caudales y su calidad físico-química y bacteriológica; las tasas de recarga en dichos puntos y la composición química de las aguas introducidas; los indicadores del comportamiento hidrogeológico del acuífero a recargar, con objeto de evaluar la aptitud y respuesta del acuífero frente a las operaciones de recarga; los procedimientos y dispositivos necesarios para efectuar la recarga, ya sean superficiales (balsas, zanjas y actuaciones en cauces) o subterráneos (pozos de inyección, galerías, drenes), y la vida útil de las instalaciones de recarga.

Finalmente, se determinará el número de puntos de recarga artificial y la evolución temporal de los volúmenes de recarga para cada masa de agua subterránea.

El apartado 2.3.2. de la Instrucción sobre las masas de aguas subterráneas establece que en la descripción general de la demarcación hidrográfica, en relación con las masas de aguas subterráneas en riesgo de no alcanzar los objetivos ambientales, se incluirán respecto a la recarga artificial: sistemas e instalaciones; ubicación de los puntos de masas subterráneas, en los que tiene lugar directamente la recarga artificial; volúmenes y tasada de recarga en dichos puntos, y origen y composición química de agua de recarga.

Igualmente, se establece que en cada demarcación hidrográfica se indicarán las presiones antropogenias significativas a que están expuestas las masas de agua subterránea, entre las que se encuentra la recarga artificial (apartado 3.2.3). Por otro lado, en el estudio de cada sistema de explotación de recursos se contendrá entre otros aspectos la recarga artificial de acuíferos (apartado 3.5.1.1).

Por último, hay que manifestar que los planes hidrológicos de cuenca que se están elaborando en la actualidad en España (con base en la citada Instrucción) tienen como uno de sus pilares fundamentales la definición de programas de medidas que permitan alcanzar el buen estado de las masas de agua, de conformidad con la Directiva Marco del Agua. Dentro de las medidas básicas a incluir en los planes hidrológicos de cuenca se incorporarán "las directrices para la recarga de acuíferos" (art. 8.2.1.1.2 de la Instrucción de Planificación Hidrológica).

e) Real Decreto $N^{\circ} \mathbf{1 . 6 2 0} / 2007$, de 7 de diciembre, por el que se establece el régimen jurídico de la reutilización de las aguas depuradas

Se contempla como uso ambiental de las aguas residuales depuradas (es decir, aquellas que han sido sometidas a un proceso de tratamiento adicional 
o complementario que permite adecuar su calidad al uso al que se dedican) el destinarse a:

"5.1. c) la recarga de acuíferos por percolación localizada a través de terrenos.

\subsection{Recarga de acuíferos por inyección directa".}

\section{f) Ley No 9/2010, de 30 de julio, de Aguas de la Comunidad Autónoma de Andalucía}

La Ley No 9/2010, de 30 de julio, de Aguas de la Comunidad Autónoma de Andalucía, define "recarga artificial" como el "conjunto de técnicas que permiten, mediante intervención programada e introducción directa o inducida de agua en un acuífero, incrementar el grado de garantía y disponibilidad de los recursos hídricos, así como actuar sobre la calidad" (art. 4, apartado 16).

El artículo 56 regula la recarga artificial en las masas de agua subterránea en los siguientes términos:

1. La recarga artificial o almacenamiento temporal para aumentar la regulación de recursos hídricos o recuperar masas de agua en riesgo podrá hacerla de oficio la consejería competente en materia de agua y, previa su autorización, la comunidad de usuarios constituida sobre la correspondiente masa de agua subterránea o un usuario singular.

2. A la solicitud de autorización se acompañará:

a) Informe hidrogeológico suscrito por personal técnico competente donde figure una caracterización completa de la masa de agua subterránea, y claramente definida la estructura del almacén y sus límites.

b) Justificación de la necesidad de efectuar la recarga y destino que se dará al agua almacenada.

c) Volumen de agua a inyectar y previsión de su movimiento.

d) Documento que acredite la disponibilidad de recursos y calidad del agua a inyectar, así como posibles interacciones con el agua del acuífero.

e) Programa de recarga y extracción, en el que se tendrá en cuenta la explotación de las masas de agua subterránea según lo dispuesto por los planes de sequía, en el caso de que existan.

3. La persona titular de la autorización de la recarga dispondrá de los volúmenes de agua que expresamente autorice la consejería competente en materia de agua, con las limitaciones que se establezcan con motivo de dicha autorización. La persona titular de la autorización de recarga podrá solicitar de la consejería competente en materia de agua la fijación de un perímetro de protección en el entorno de la zona de recarga, en los términos previstos en el artículo 55.

Como se deduce de este precepto, la RAA en Andalucía está sometida a autorización de la Agencia Andaluza del Agua, para lo que previamente el solicitante tiene que justificar la necesidad de la recarga, el volumen a inyectar, 
interacción con el agua del acuífero, y otras consideraciones de carácter estrictamente técnico.

\subsubsection{En síntesis}

Dado dicho panorama, hay claramente una regulación desperdigada, doble o triplemente regulada en distintos niveles jerárquicos -que no necesariamente son coincidentes entre sí- y cuyo efecto es la descoordinación.

Así pues, producto de lo antes descrito se han producido importantes consecuencias -conocida es la condena a España por su retraso en la implementación de la Directiva Marco del Agua con relación a los planes hidrológicos ${ }^{29}-$, y que en materia de recarga de acuíferos no se haya registrado un avance significativo en los últimos años.

Ello hace especialmente dificultosa tanto la implementación como la operación del sistema de RAA en España, de forma tal que a estas alturas aún hay mucho por desarrollar. Pese a este entramado, han florecido varios proyectos de RAA, como los ya indicados.

\subsection{La recarga de acuíferos en Australia ${ }^{30}$}

\subsubsection{Las iniciativas de abastecimiento de agua ante la dura realidad}

Del mismo modo que en otras latitudes y ante la creciente variabilidad general de las condiciones climáticas, que en algunas zonas resultan extremas, en el caso de Australia adquirió algunos ribetes de especial dramatismo, atendidas numerosas catástrofes asociadas a la sequía extrema. Aquello permitió

\footnotetext{
29 Tribunal de Justicia de la Unión Europea (en línea), sentencia dictada en causa rol C-403-2011.

${ }^{30}$ Cabe señalar que Australia está dividida en seis estados, dos territorios continentales y otros territorios menores. Los estados son Nueva Gales del Sur (NSM), Queensland (QLD), Australia Meridional (SA), Tasnamia (TAS), Victoria (VIC) y Australia Occidental (WA).

Los dos territorios continentales son el Territorio del Norte (NT) y el Territorio de la Capital Australiana (ACT). En la mayor parte de sus asuntos, los territorios funcionan de manera similar a los estados; sin embargo, el Parlamento de la Confederación tiene el poder de anular cualquier legislación de los parlamentos estatales y territoriales. Cada estado y territorio tiene su propia legislatura (unicameral en el caso del Territorio del Norte, el Territorio de la Capital Australiana y Queensland, y bicameral en los restantes estados). La cámara baja es conocida como Asamblea Legislativa (Cámara de la Asamblea en Australia Meridional y Tasmania) y la cámara alta es Ilamada Consejo Legislativo.

El jefe de Gobierno de cada estado y territorio es denominado premier y chief minister, respectivamente. La reina es representada en los estados por un gobernador, en el Territorio del Norte por un administrador, y en el Territorio de la Capital Australiana por el gobernador general.

Australia tiene también, además, varios territorios menores y territorios externos habitados [Isla Norfolk, Isla de Navidad e Islas Cocos (Keeling)] y deshabitados.

Estos datos servirán para entender las consideraciones que siguen.
} 
la confluencia del gobierno, la industria y los ciudadanos en torno a la idea de dar prioridad a un proceso de análisis y mejora en torno a los recursos hídricos, lo que se manifestó en especial con relación a un proceso de mejora en los procesos de gestión del agua.

Este hincapié llevó a considerar distintos enfoques, cambios en la gobernanza, modificaciones en las conductas e innovación tecnológica, lo que supuso tomar decisiones difíciles y mucha generosidad de los actores involucrados. Luego, dado aquello, el resultado de la experiencia y el enfoque de Australia al abordar los desafíos en materia de gestión del agua permite sostener que están entre los más progresistas del mundo.

Ello se basa en la existencia hasta ahora en un plan general, que consideró la elaboración de una nueva gobernanza del agua radicada en la National Water Commission (NWC), que cuenta con el apoyo de la Comisión Australiana de Comercio (Austrade), el Departamento de Innovación, Industria, Ciencia e Investigación (DIISR), Water Australia y socios de la industria de abastecimiento de agua a las poblaciones, en miras de generar soluciones innovadoras desarroIladas por las empresas y los grupos de investigación a favor de la gestión del agua para sectores urbanos, agrícolas e industriales de toda Australia ${ }^{31}$.

En este escenario, se desarrolló una iniciativa destinada a generar reformas estructurales de la regulación de aguas, concretadas en la Iniciativa Nacional del Agua (NWI), sucesora de la primera ronda de reformas iniciada en 1994, que estableció un cronograma consensuado de reformas monitoreado por la Comisión Nacional del Agua (NWC) y sujeto a un informe bienal, desarrollado por una serie de entidades.

A tales efectos, la Oficina de Meteorología -que actúa como instancia técnica revisora- elabora anualmente la Cuenta Nacional del Agua, que brinda invaluable información sobre las reservas y los flujos de agua, los derechos al agua y el uso del agua, e informa de manera transparente sobre los volúmenes de agua comercializados, extraídos y gestionados con fines económicos, sociales, culturales y ambientales en toda Australia. Asimismo, la Organización de Investigación Científica e Industrial de la Mancomunidad (CSIRO, por sus siglas en inglés), la principal institución científica de la nación, está activamente involucrada en la investigación de aguas de superficie y subterráneas, sistemas de aguas urbanas y calidad, clima y adaptación, además de otras cuestiones vitales concernientes al sector acuífero. Y, en fin, otros entes del gobierno australiano, como la Comisión de Productividad, están involucrados en la revisión del rendimiento económico de la industria, para recomendar más reformas que puedan mejorar la eficiencia económica del sector.

31 Austrade (2011), p. 3. 
Todo ello ha redundado en que la experiencia de Australia en gobernanza, gestión de sistemas, tecnologías de tratamiento de agua, gestión ambiental y fluvial, así como en otros campos, es altamente respetada y promovida ${ }^{32}$.

\subsubsection{Impacto en la construcción regulatoria}

\section{a) Aspectos iniciales}

Dados los factores antes señalados -en virtud sobre todo de su configuración como un Estado federal-, la regulación en Australia se encuentra dividida o fragmentada entre sus diferentes territorios, en un contexto de gestión o manejo tradicional que considera licencias y explotación consiguiente, tanto de las aguas superficiales como de las subterráneas, y concedidas por las autoridades respectivas.

Lo anterior no implica necesariamente manejo asociado ni gestión integrada que pudiera comprender intercepción de aguas lluvias, extracción de aguas superficiales y subterráneas, desalación o recarga, lo que genera una gestión no integrada de recursos hídricos. Y la consecuencia de ello es que, sin la existencia o consideración de aquello, no pueden generarse incrementos en calidad ni cantidad de recursos hídricos ${ }^{33}$.

Sin embargo, a partir de su experiencia, se realizó esa integración.

\section{b) Recomendaciones}

Dada la experiencia acumulada, y la integración de fuerzas representativas de distintos intereses, la NWC impulsó una agenda destinada a integrar políticas y regulaciones diferentes, unificando los sistemas de licenciamientos, condiciones de operación y de protección de los acuíferos, y, de esta forma, simplificar la gestión del agua, de por sí muy compleja desde un punto de vista fáctico. Frente a lo anterior, propuso -y fue aceptado- considerar la necesidad de articular un régimen de propiedad sobre los derechos que fortaleciera la seguridad, la eficiencia económica y los bajos costos de administración, así como la investigación de los impactos de usos urbanos de agua basados en la RAA o MAR ${ }^{34}$.

Sin esos arreglos institucionales -reclamados en su oportunidad por parte de la NWC-, se impedía el efectivo y eficiente desarrollo de una activa y sustentable industria de recarga. Por el contrario, la ausencia o falta de claridad

\footnotetext{
32 Austrade (2011), p. 6.

33 National Water Commission (2009), p. 45.

34 National Water Commission (2009), p. 47.
} 
en torno a títulos bien definidos creaban, consecuencialmente, impedimentos para el desarrollo de esta clase de iniciativas o cualquier otra destinada a generar mejoras, con efectos en bancos de aguas, disputas y potenciales impactos en la disponibilidad, o iniciativas respecto de aguas subterráneas, así como la generación de ecosistemas altamente frágiles, sobre todo en vistas de decisiones sobre asignación y/o gestión de recursos hídricos, para lo que se requiere de información efectiva y certera, a fin de generar iniciativas de regulación en general y de recarga en particular.

Adicionalmente, se propuso -y obtuvo- la indispensable ordenación territorial en torno a los usos de la tierra a partir de la calificación y disponibilidad de aguas, considerando una necesaria coordinación en los estados involucrados, básicamente Australia Meridional (SA) y Territorio de la Capital Australiana (ACT), a lo que se sumó Queensland (QLD).

Lo anterior generó distintos instrumentos de reconocimiento de la técnica de RAA en las sucesivas Water Management Act de 1999 y 2000, en cada uno de los territorios señalados con mayor o menor desarrollo de sus regulaciones, siendo común que se comprendieran con base en las indicaciones de la NWC, los siguientes elementos ${ }^{35}$ : aprobación de obras para extracción de aguas superficiales; licencias para extracción de aguas superficiales; aprobación de proyectos de uso, inyección e infiltración; aprobación de obras para exploración de aguas subterráneas, y licencias para extracción de aguas subterráneas y uso de acuíferos.

\section{c) El aprendizaje: La tríada virtuosa en materia regulatoria}

Todo lo anterior generó una propuesta dentro del marco de la NWI que liga tres cuestiones fundamentales, en miras a la eficiencia del uso del agua con base en título, asignación y uso obligatorio ${ }^{36}$.

El primero define las características y el número o unidad o volumen del total del acuífero asignado individualmente.

La segunda define el proceso para la toma de decisión periódica de determinación de agua variable con base en la disponibilidad.

Y lo tercero prescribe o proscribe la obligación de utilización del agua conforme los usos existentes y sus efectos.

La consecuencia de ello es una vinculación virtuosa, en miras a la eficiencia y eficacia de los usos, entre ordenación territorial, disponibilidad y sustentabilidad,

35 National Water Commission (2011 a), p. 19.

36 National Water Commission (2011 b), pp. 6-7. 
que significó la implementación de numerosas iniciativas reales y concretas en este campo; todas ellas con éxito significativo.

Sin embargo, cabe considerar que la NWC, por el término del período fijado previamente para su trabajo, fue declarada concluida y dejó de funcionar desde el 1 de enero de 2015, para transmitir esencialmente sus funciones a la Productivity Commission. Igualmente, otras funciones fueron transferidas al Australian Bureau of Agricultural and Resource Economics and Sciences, también al Department of the Environment, en especial los relativos a la National Partnership Agreement on Implementing Water Reform, que aún mantiene tareas pendientes.

En cualquier caso, los continuadores han seguido el camino trazado.

\section{En este contexto, las potestades administrativas de la Dirección General de Aguas proyectadas a la RAA}

\subsection{Las potestades de la $\mathrm{DGA}^{37}$}

Ahora, volviendo a nuestra regulación $-\mathrm{y}$ volviendo al objeto concreto, respecto del cual todo lo dicho hasta ahora sirve-, cabe señalar que es en la Dirección General de Aguas (DGA) donde se encuentra radicado un conjunto significativo de potestades administrativas en materia de aguas, que se desarroIlan compartimentada o conjuntamente, las que sucinta y esquemáticamente se pasan a indicar.

Pese a lo que se verá, podrá ir apreciándose que, a diferencia de los dos ejemplos vistos, no contamos con un entramado normativo, sino solo con pocas piezas, en este campo.

\subsubsection{La actividad ordinaria de gestión de las aguas por la DGA}

Para lo cual realizaremos una distinción de acuerdo al tipo de potestad que se ejerce entre dos niveles o tipos de potestades. Como se verá más adelante, ellas se entrecruzan para tratar la recarga de acuíferos.

\section{a) Asignación, autorización e información de las aguas}

En primer término, este ámbito desarrolla una actividad principal de asignación, autorización e información de las aguas, y su actividad se concreta en: (i) constitución de derechos de aprovechamiento de aguas (técnica concesional); (ii) constitución de derechos en materia de aguas subterráneas (técnica concesional), y (iii) limitaciones para el otorgamiento de nuevos derechos (reservas, agotamientos, declaraciones).

37 Se sigue el orden propuesto en Rojas (2016), pp. 151-193. 


\section{b) Policía general}

Igualmente desarrolla una actividad también principal de policía administrativa (ordenación, inspección, sanción), actividad que, en el ámbito de la regulación, se manifiesta en lo que sigue: (i) autorización en materia de cambios por traslado, por fuente de abastecimiento relativos a los derechos ya otorgados (técnica autorizacional); (ii) autorización en materia de obras hidráulicas (técnica autorizacional); (iii) autorización en materia de uso de cauces (técnica autorizacional); (iv) ordenación por información; ( $v$ ) ordenación de relaciones (actividad registral); (vi) ablación como ampliación de situaciones pasivas; (vii) ablación como creación de nuevas situaciones pasivas; (viii) inspección o fiscalización, que comprende a su turno la inspección preventiva, la inspección paliativa, la inspección correctiva, y el control administrativo de las organizaciones de usuarios de aguas, y la (ix) actividad sancionatoria.

En fin, hay una serie de atribuciones -como competencia genérica- en materia de recursos hídricos asignados.

\subsubsection{La actividad extraordinaria y excepcional de gestión de las aguas por la DGA, en caso de extrema sequía}

A este respecto, desarrolla una actividad de intervención administrativa extraordinaria supuesta la declaración formal de extrema sequía, siendo sus efectos los que siguen: (i) redistribución de las aguas; (ii) suspensión de potestad de distribución (ordenación o regulación) de las aguas de las juntas de vigilancia; (iii) suspensión de seccionamientos; (iv) indemnización en caso que haya que preferir a algún uso, y (v) "redistribución" de la DGA cuando no hay junta de vigilancia.

\subsection{Configuración de las potestades de la DGA en materia de aguas subterráneas. Visión crítica $^{38}$}

En esta parte, en general puede sostenerse que la regulación acerca de las aguas subterráneas en la ley -el Código de Aguas (CAg)-, en cuanto instrumento base de cualquier desarrollo normativo inferior, aparece como altamente deficitaria, pues corresponde a tan solo un puñado de disposiciones, siendo alrededor de 30 de un total de 317 disposiciones permanentes y 13 transitorias, denotando de este modo una inadecuada preocupación por las aguas subterráneas. En este mismo orden, ellas se refieren a aspectos esenciales, concentrándose en la conceptualización y nociones generales; origen de los

\footnotetext{
${ }^{38}$ En general se sigue a Rivera (2015), pp. 225-230.
} 
derechos de aprovechamiento; protección y limitaciones a su explotación, y gestión colectiva de derechos de aguas subterráneas.

En cambio, en virtud del "Reglamento sobre normas de exploración y explotación de aguas subterráneas" (Decreto № 203, de 20 de mayo de 2013, publicado en el Diario Oficial el 7 de marzo de 2014), se produce un mayor desarrollo de la regulación de las aguas subterráneas.

Se destaca que, en sus considerandos, se reconoce la necesidad de reglamentar la exploración y explotación de aguas subterráneas y otorgar certeza jurídica y técnica a los usuarios en un contexto de sustentabilidad y eficacia; todo ello sin afectar el ejercicio de derechos constituidos sobre las mismas aguas. Asimismo, se advierte la procedencia de profundizar ciertos conceptos técnicos y de incorporar otros nuevos para enfrentar la diversidad de aristas que se presentan en este tema. Este instrumento comprende los siguientes capítulos:

a) Exploración de aguas subterráneas (en inmuebles de dominio privado y en bienes nacionales), y

b) Explotación de aguas subterráneas (disposiciones generales; áreas de protección; limitaciones a la explotación; comunidades de aguas subterráneas; cambio de punto de captación y/o restitución; cambio de fuente de abastecimiento; puntos alternativos de captación y/o restitución; recarga artificial; disposiciones especiales, y disposiciones transitorias) ${ }^{39}$.

En fin, en el tema particular de este trabajo, especialmente a partir de la potestad para la constitución de derechos de agua, y en relación con los títulos concesionales que recaen sobre aguas subterráneas, es posible realizar los siguientes comentarios.

Como primera cuestión -lo que salta a la vista de inmediato-, la regulación acerca de la exploración, la explotación y la forma de constitución de derechos de aprovechamiento de aguas subterráneas, así como las formas de limitaciones (por medio de áreas de protección o de restricción) están principalísimamente desarrolladas en el Reglamento de Aguas Subterráneas, y no en la ley. Ello contraría el tipo de norma usada para regular las titularidades privadas sobre bienes o derechos, en la medida en que no es una ley, sino un reglamento, la que establece las modalidades de adquisición y limitación, lo que en principio es inadmisible desde el punto de vista de la técnica normativa, dado que en la misma regulación reglamentaria se contienen importantes potestades administrativas, que en último término deben sostener su correlato regulatorio en la ley siquiera de manera general, lo que no se cumple en esta situación.

Y, como segunda cuestión, se hace presente una diferencia igualmente inadmisible relativa al fundamento normativo de la constitución de derechos de

39 RiverA (2015), pp. 230-232. 
agua subterránea en relación con los de carácter superficial, encontrando su fundamento principal en un reglamento, y en el segundo en la ley. En efecto, mientras la regulación respecto de los derechos de aguas superficiales se contiene esencialmente en la ley, en el caso de las aguas subterráneas, se contiene esencialmente en un reglamento.

Como fundamento, ya no técnico-normativo, sino que en el orden jurídico concreto, es posible sostener igual exigencia, pues en virtud del numeral 24 del artículo 19 de la CPR se establece que la Constitución asegura a todas las personas "El derecho de propiedad en sus diversas especies sobre toda clase de bienes corporales o incorporales. Sólo la ley puede establecer el modo de adquirir la propiedad, de usar, gozar y disponer de ella y las limitaciones y obligaciones que deriven de su función social".

En consecuencia, y dado que los derechos de aguas subterráneas son un tipo de bien -un derecho real administrativo, específicamente-, su configuración principal y secundaria debe estar regulada en una ley, en especial su régimen o modo de adquisición, uso y goce. Esto, en la especie, no ocurre.

\subsection{Proyección de lo anterior al INDICIO DE REGULACIÓN de la RAA en nuestro ordenamiento jurídico}

\subsubsection{Código de Aguas}

Su escaso fundamento normativo se encuentra en los artículos 66, inciso $2^{\circ}$, y 67 , inciso $1^{\circ}$ en su segunda parte, del CAg. Estos más bien tienen carácter atributivo de potestades, pero poco dicen con respecto al modo específico en que se obtienen tanto las autorizaciones como los derechos de aprovechamiento de aguas vinculados a la recarga.

En efecto, en virtud del artículo 66, inciso $2^{\circ}$, previa autorización de la Dirección General de Aguas, cualquier persona podrá ejecutar obras para la recarga artificial de acuíferos, no siendo necesario que anteriormente se haya declarado área de restricción. Dado lo anterior, y siempre que realice la obra de recarga, se le da solo una preferencia para que se le constituya un derecho de aprovechamiento con carácter de provisional, sobre las aguas subterráneas derivadas de tales obras y mientras ellas se mantengan.

Y, por su lado, el artículo 67 establece que los derechos de aprovechamiento otorgados con carácter provisional en virtud del artículo e inciso ya revisados, no se podrán transformar en definitivos aun cuando cumplan con las condiciones, pues en el caso de las obras de recarga únicamente se dan derechos con carácter de provisionales y mientras persista la recarga artificial. 


\subsubsection{D.S. N$^{\circ} 203$ de 2013, Reglamento de Aguas Subterráneas (publicado en el Diario Oficial el 7 de marzo de 2014)}

Acá igualmente se contemplan pocas normas, del artículo 47 al 50, que se pasan a analizar.

En esta fase, se desarrolla más y con detalle el procedimiento administrativo correspondiente tanto a la autorización de obras de RAA, como al uso de derechos provisionales para la recarga.

Conforme lo dispuesto en el artículo 47, cualquier persona puede ejecutar obras para la RAA, para lo cual debe obtenerse una autorización previa del proyecto por parte de la Dirección General de Aguas.

Luego, en virtud del artículo 48, la solicitud de autorización para ejecutar obras para la recarga artificial de acuíferos se tramitará conforme al procedimiento administrativo establecido en el artículo 130 y siguientes del Código de Aguas.

Adicionalmente, dispone que la solicitud debe contener los siguientes antecedentes:

1. Nombre, rol único tributario y demás antecedentes para la individualización del solicitante y de su representante legal, si corresponde.

2. Una descripción de la naturaleza física y situación jurídica del agua a utilizar en la recarga artificial, debiendo acompañar los documentos necesarios para acreditar el dominio vigente del derecho de aprovechamiento de agua, si así correspondiere.

3. Una memoria técnica que contenga, a lo menos, lo siguiente:

a) Descripción del proyecto de recarga artificial, que debe especificar: i. Tipo y disposición de obras; ii. Plan de operación y mantención, y iii. Modelación del efecto de la recarga sobre la cantidad de las aguas del Sector Hidrogeológico de Aprovechamiento Común.

b) Descripción y características geológicas e hidrogeológicas del sector de la recarga, que debe contemplar a lo menos: $i$. Características de la zona no saturada; ii. Permeabilidad, almacenamiento y geometría del sector influenciado directamente por la recarga; iii. Información de registros conocidos sobre el nivel del acuífero del sector, y iv. Caracterización de la calidad de las aguas del sector de la recarga.

c) Caracterización de la calidad de las aguas que se infiltrarán artificialmente. Además, la Dirección General de Aguas podrá requerir al solicitante la elaboración de análisis fisicoquímicos o bacteriológicos adicionales del agua que se infiltraría, cuando las características del proyecto de infiltración artificial así lo ameriten.

d) Plan de monitoreo, que debe contemplar al menos: $i$. Monitoreo de la zona aledaña al emplazamiento de la obra de infiltración, con el objeto de 
observar el comportamiento de las aguas infiltradas, ya sea mediante la medición de niveles o no, a fin de evitar riesgos de inundaciones o afecciones a terceros; ii. Monitoreo de la calidad de las aguas en el sector influenciado directamente por la recarga, y iii. Monitoreo del caudal y volumen de recarga.

e) Plan de acción frente a la eventual contaminación del sector influenciado directamente por la recarga.

Enseguida, de acuerdo al artículo 49 se establece perentoriamente que Dirección General de Aguas debe aprobar las obras de infiltración cuando el proyecto presentado cumpla con los requisitos establecidos en los artículos 47 y 48, y no provoque la colmatación del acuífero ni la contaminación de las aguas.

En fin, en el artículo 50 se regula a este nivel reglamentario la solicitud de derechos de aprovechamiento de aguas de carácter provisional asociada a la obra de recarga artificial aprobada.

La primera regla a este respecto importa que para esta solicitud-del mismo modo que para la solicitud de obras para recarga- se deberá aplicar el procedimiento administrativo previsto en el párrafo $1^{\circ}$ del Título I del Libro Segundo del Código de Aguas, con el añadido de que esta solicitud debe contener los antecedentes señalados en el artículo 19 del Reglamento, que especifica los requisitos técnicos en materia de solicitudes de derechos de aprovechamiento de aguas subterráneas.

La segunda regla consiste en que, para hacer efectiva la preferencia establecida en el artículo 66 inciso segundo del Código de Aguas, el solicitante deberá indicar en su solicitud el hecho de contar con la aprobación de una obra de recarga de que trata el artículo anterior, identificando la resolución respectiva. Se considerará esta preferencia solo sobre el Sector Hidrogeológico de Aprovechamiento Común influenciado directamente por la recarga. Excepcionalmente, esta preferencia podrá considerarse en un Sector Hidrogeológico de Aprovechamiento Común distinto al que recibe la recarga artificial siempre y cuando esté claramente interrelacionado, y el o los puntos de captación del derecho provisional se ubiquen en una zona directamente influenciada por la recarga artificial. Ambas situaciones deben ser acreditadas por el solicitante y verificadas por la DGA; en caso contrario, la petición será denegada.

Por último, la DGA deberá constituir -por consiguiente, con carácter no disponible- el derecho de aprovechamiento de carácter provisional cuando la solicitud cumpla con los siguientes requisitos: a) que sea legalmente procedente conforme a las normas establecidas en el Código de Aguas y su Reglamento; b) que efectivamente exista la obra de recarga artificial aprobada a favor del solicitante y que esta se encuentre operando; c) que el solicitante presente un balance hídrico que, considerando el volumen de agua infiltrado, las pérdidas existentes y los tiempos de circulación, permita definir el volumen adicional que 
la infiltración artificial genera en el Sector Hidrogeológico de Aprovechamiento Común donde se ubica el punto de captación del derecho de aguas solicitado, y d) que el ejercicio del derecho de aprovechamiento provisional que se constituya no provoque perjuicio a derechos de aprovechamiento de aguas existentes (en respeto del salve iure terti).

\subsubsection{Complemento por medio de soft law}

A lo anterior cabe agregar dos instrumentos indicativos de actuación del interesado, consistentes en la "Guía metodológica para presentación de proyectos de recarga artificial" 40 y en la "Guía para la presentación de solicitudes de derechos de aprovechamiento provisionales de aguas subterráneas con cargo a recarga artificial" 41 , ambos de noviembre de 2016.

Se trata, como se sabe y en principio, de directivas que la autoridad administrativa imparte a los funcionarios o agentes públicos, relacionadas con el correcto cumplimiento de la ley o con la necesidad de desarrollar una más eficaz y expedita función, y está dirigidos a la propia Administración, no a los particulares, frente a los cuales en principio no se pueden hacer valer ${ }^{42}$. Por tanto, ellas no tienen más fuerza que la que les corresponde en razón de las actividades y sujetos adscritos a la función pública correspondiente, siendo una expresión de soft law público con efectos ad intra.

Sin embargo, lo cierto es que una enorme cantidad de estos instrumentos, como recomendaciones directivas, guías operativas y manuales de operación, extienden su campo de aplicación más allá de las áreas estrictamente administrativo-funcionarias, "obligando" con sus disposiciones también a los particulares en sus solicitudes o ante las cargas que les impone el servicio respectivo. Estamos acá en situaciones genuinas de soft law público con efectos ad extra, que pueden tener efecto individual o universal y, en ese caso, tienen efecto regulador, como se estima sería el caso análizado ${ }^{43}$.

Del primero, destaca la referencia contenida en el numeral 2.1.7., relativo a la necesidad del proyecto de contar con RCA favorable, de manera previa a la resolución de autorización de recarga artificial, lo que será atendido más adelante.

Y del segundo, la ratificación de contar para la presentación de solicitudes de derechos de aprovechamiento provisionales de aguas subterráneas con

\footnotetext{
40 Dirección General de Aguas. Departamento de Administración de Recursos Hídricos (2016a).

41 Dirección General de Aguas. Departamento de Administración de Recursos Hídricos (2016b).

42 Cordero (2015), p. 177.

43 Sarmiento (2008), pp. 121-124.
} 
cargo a recarga artificial, con el número de resolución y fecha de aprobación del proyecto de recarga así como el número de resolución y fecha de recepción del mismo, como condición sin la cual no es posible dar lugar a tramitar la petición de la especie.

\section{Comentarios críticos y de mejora regulatoria}

Como consecuencia de lo anterior, es posible sostener algunos comentarios críticos que se pasan a desarrollar.

\subsection{Falta y necesidad de una regulación unitaria sobre la RAA}

Como ha quedado de manifiesto, solo existe de manera tangencial en el CAg y en el Reglamento citado. Dada su importancia, debiera encontrarse regulada en una ley donde se estableciera un sistema claro de orden procedimental y sustancial, sobre todo en lo que dice relación con la titularidad de los derechos creados.

Esto, al no constituir un sistema de derechos claro y reforzado, no incentiva en modo alguno las cuantiosas inversiones que deben realizarse para montar un sistema de recarga.

En este mismo orden, la actual regulación solo contempla un sistema procedimental -de naturaleza administrativa- que se sigue ante la DGA para la generación de derechos de carácter provisional, sin que exista la posibilidad para que estos puedan transformarse en definitivos dada una prohibición expresa.

Valga, por consiguiente, el mismo comentario que en el anterior caso.

\subsection{Financiación de la RAA: Relación con la titularidad para el incentivo a la inversión privada.}

Dado que la regulación discurre sobre la base de que el particular es el que hace la inversión, pero no se le genera un derecho definitivo (no "bancarizable", por tanto) y no existe a la fecha un instrumento para una cofinanciación a través de algún mecanismo de ayudas públicas -típicamente a través de subsidios otorgados por la Comisión Nacional de Riego-, al no contemplarlas directamente en la Ley $N^{\circ}$ 18.450, de Fomento a la Inversión Privada en Obras de Riego y Drenaje, resulta absolutamente inviable un proyecto individual o comunitario de RAA por las enormes inversiones que ello requiere.

Sucede, sin embargo, que en noviembre de 2013 la Ley $N^{\circ} 18.450$ es modificada con el objetivo de poder abordar además los proyectos integrales de riego y drenaje, de uso múltiple, cuyo costo supere las 30.000 UF con un tope máximo de 250.000 UF. Con estas nuevas disposiciones, lo que se busca es potenciar la actividad de las organizaciones de regantes, para lo que se 
focaliza parte de los recursos para bonificar proyectos que consideren obras multipropósito, como son los proyectos que, además del riego, recuperen la calidad de las aguas de riego contaminadas, posibiliten la infiltración para la recarga de acuíferos, fomenten el uso y generación de energías renovables no convencionales en la agricultura, proyectos específicos para apoyar y desarrollar la agricultura sustentable, entre otras áreas.

Esto, en cualquier caso, debiera corregirse, por la vía de crear un subsidio especial directo, y no esta vía indirecta, dada la importancia estratégica de estos proyectos, con alta posibilidad de solucionar problemas actuales.

\subsection{Escasa experiencia de recarga artificial de acuíferos}

No ha habido, entendemos que por lo mismo indicado en el numeral anterior, experiencia de RAA en los términos del Código y Reglamento. Así pues, los proyectos realizados de los cuales se dio cuenta en la introducción y en la sección I de este trabajo, solo han tenido carácter experimental o "piloto" y sin demasiado éxito.

Se cree que una posible respuesta se encuentra en dos factores: por lo indicado, el escaso desarrollo normativo que afecciona la seguridad jurídica, y por lo también anotado, relativo a las cuestiones de orden financiero que afectan los aspectos económicos en esta clase de proyectos; ambos elementos constituyen un obstáculo evidente para que se lleve adelante un proyecto de esta especie.

\subsection{Dudas sobre el control de la operación}

Atendido que la situación de planta de personal de la Dirección General de Aguas no ha cambiado desde el informe de diagnóstico del Banco Mundial de 2011, y el hecho de que la actividad de control o monitoreo sobre las aguas tanto superficiales (en menor medida) como subterráneas se ha externalizado por medio de convenios con particulares cocontratantes, no existe un sistema seguro de control real, instantáneo y en línea que permita vigilar la operación de sistemas particulares, estatales o consorciados.

Por cierto, el sistema, tal cual está diseñado hasta ahora, no les reconoce papel alguno a las organizaciones de usuarios de aguas. Ello, salvo que existiera una comunidad de aguas subterráneas, en cuyo caso sí podría hacerse un control por parte de ellas.

\subsection{Dudas, de nuevo, sobre la titularidad de las aguas derivadas de la recarga y sus efectos}

Dado que con la actual configuración jurídica del sistema de RAA no hay posibilidad de generar titulos administrativos consolidados -como un derecho 
de aprovechamiento de aguas de carácter definitivo-, no existe ningún incentivo a la generación de esta clase de proyectos.

De esta manera, solo queda entregada a la iniciativa estatal la generación de estos títulos en favor de titulares de derechos permanentes a fin de reforzar su disponibilidad actual. Es decir, el interés público se privatiza cuando se realizan proyectos e inversiones que tienen destinatarios particulares, sin que aquellos corran riesgo de ninguna clase.

La vía de acción esperable sería la efectiva acción de parte de las autoridades sectoriales en el sentido de exigir un sistema de información que permita establecer un real monitoreo de las aguas subterráneas; administración comunitaria por medio de una organizada comunidad de aguas subterráneas, e inversiones consistentes con la sustentabilidad, utilizando los instrumentos que hoy en día les entrega la regulación, la que se considera suficiente para estos fines. Esto, pues la DGA tiene atribuciones pertinentes e instrumentos -especialmente en situación de sequía- para decretar medidas que les permitan a los propios titulares enfrentar las nuevas situaciones derivadas de la sequía permanente.

En suma, la consecuencia de todo lo señalado, es la evidente afirmación consecuencial de una regulación absolutamente insuficiente en esta materia y que requiere una rápida implementación.

Todo lo antes dicho se afirma en que, evidentemente, dos disposiciones extraordinariamente sucintas en el CAg, cuatro en el Reglamento, algunas más en instrumentos indicativos y una final a nivel de simple acto administrativo, bajo ninguna perspectiva constituyen un régimen jurídico para la adquisición, uso y pérdida de esta clase de iniciativas, mas cuando se las asocia de manera indisoluble a concesiones administrativas de aguas, como son al final en todos los casos, características y orígenes los derechos de aprovechamiento de aguas existentes en nuestra regulación.

Es especialmente destacable que, en virtud de las mismas, no se asegura a quien proyecta o realiza un proyecto de RAA la constitución de un derecho -solo da una preferencia-, cuando a más de lo anterior alcanzaría solo para generar un derecho de aguas subterráneas de carácter provisional, lo que al cabo del tiempo prefijado de control de sus caudales, e incluso cumpliendo con condiciones de sustentabilidad demostradas por medio de los informes periódicos que se fijan como condición de su otorgamiento y ejercicio, la DGA puede igualmente negar la transformación del derecho provisional en definitivo.

Lo anterior no genera incentivos reales para la RAA por emprendimientos particulares y prueba de lo ello es que lo que hay a la fecha solo son iniciativas estatales. 


\subsection{En fin, si alguien resulta dañado, ¿quién, cómo y en virtud de qué responde?}

Esta pregunta es esencial en la elaboracion de una política y plan públicos, y no es respondida de ninguna manera por el sistema hasta ahora establecido, el que solo ve los aspectos esencialmente procedimentales.

Evidentemente, esta cuestión -junto a los otros aspectos destacados en menos- es sumamente importante, y en la medida en que no haya respuestas del sistema jurídico o de la autoridad, seguirán realizandose solo experiencias "piloto" o realizándose intervenciones en caso de urgencias.

Así, hay silencio acerca del sistema de responsabilidad, del título de imputación y de la atribución, todas cuestiones esenciales que son omitidas por las reglas revisadas, existiendo una distancia sideral entre esta cuestión específica y los sistemas de responsabilidad vigentes, generando el efecto de la desafección tanto de las autoridades públicas como de los particulares para embarcarse en proyectos de esta naturaleza. Que no haya reglas claras y definidas, en nada ayuda.

Por supuesto, eso no es lo que se quiere, o debiera esperarse, y por ello este trabajo crítico pretende constituir un aporte a la discusión de esta técnica tan relevante.

\section{Conclusiones}

Al finalizar este trabajo es posible arribar al siguiente grupo de conclusiones:

1) La recarga artificial de acuíferos (RAA) constituye una técnica que se usa con bastante éxito en varias partes del mundo y constituye un instrumento que coadyuva a enfrentar tanto la creciente demanda de agua para uso industrial como las cada vez más presentes y preocupantes consecuencias del cambio climático, en especial todas aquellas que derivan de las sequías prolongadas.

2) Analizados los ejemplos de España y Australia es posible sostener, en primer término, que la existencia de regulación no garantiza su implementación exitosa, mas cuando esta se construye de modo descoordinado y no sistemático, y opera con diferentes estadios, sin que ellos se vinculen, y, en segundo término, que solo consensos logrados entre todos los actores -autoridad política, autoridades técnicas, industrias y comunidades organizadas- permiten sustentar y convertir en exitoso un instrumento que a la vez de ser técnico es también jurídico, y por lo mismo, precisa que sea cumplido para su correcto funcionamiento.

3) Del análisis efectuado aparece que Chile tiene una regulación escasa y no desarrollada en todas las complejidades que se analizan en este trabajo, que incluso no alcanzó a tratar otras, como la faz ambiental. En efecto, en su escasa normación (considerando los tres niveles estudiados) no se da respuesta 
a numerosos aspectos tan significativos como los tratados acá solamente en sus facetas procedimentales, como son la generación de títulos suficientes y definidos en torno a las aguas de recarga; los permisos a que da lugar; implicancias en materia de calidad; aspectos relacionados con la titularidad de las obras; seguridades asociadas a los usos del agua; aspectos de orden financiero de las cuantiosas inversiones requeridas por esta técnica, entre varias otras.

En fin, se estima que la duda más relevante dice relación con los tres aspectos relevantes que deben darse en toda actividad: determinación de autorizaciones (quién), gestión u operación (cómo), y responsabilidades en caso de daño (por qué).

Hasta ahora, el sistema solo da cuenta en parte de lo primero, para efectos de su implementación, pero nada dice sobre el control de la operación del sistema ni hay regla alguna acerca de las responsabilidades asociadas a aquello.

\section{Bibliografía}

Austrade (2011): "La dinámica industria del agua en Australia". Disponible en: www.austrade.gov.au/.../1358/Water-Innovation-Booklet-es.pdf.aspx [visitado el 20.01.2016].

Comisión Chilena del Cobre-Cochilco (2009): "Gestión del recurso hídrico en Chile. Proyección consumo de agua en la minería del cobre 2009-2020". Disponible en: http://www.cochilco.cl/descargas/estudios/informes/agua/ proyecciones_consumo_agua_AZ_RB.pdf [visitado el 10.08.2015].

Cordero VeGa, Luis (2015): Lecciones de derecho administrativo (Santiago, Thomson Reuters-Legal Publishing).

Dirección General de Aguas (2007): "Estimaciones de demanda de agua y proyecciones futuras. Zona I Norte, regiones I a IV". Disponible en: http:// documentos.dga.cl/USO4854v1.pdf [visitado el 16.12.2016].

(2012): "Boletín Información Pluviométrica, Fluviométrica, Estado de Embalses y Aguas Subterráneas, № 405". Disponible en: http://www.dga. $\mathrm{cl} /$ productosyservicios/informacionhidrologica/Informacin\%20Mensual/ boletin012012.pdf [visitado el 16.12.2016].

(en línea): "Mapas interactivos". Disponible en: http://apps.arcgis.com/ apps/OnePane/basicviewer/index.html?appid=1f120f5a187149e0a0a30c4 ab144ddae [visitado el 15.12.2016].

Dirección General de Aguas. Departamento de administración de Recursos Hídricos (2016 a): "Guía metodológica para presentación de proyectos de recarga artificial". Disponible en: http://www.dga.cl/orientacionalpublico/guias/Guias \%20para\%20presentacion $\% 20 \mathrm{de} \% 20$ 
solicitudes/Guia_Metodologica_para_presentacion_Proyectos_de_Recarga_ Artificial_2016.pdf [28.12.2016].

(2016 b): "Guía para la presentación de solicitudes de derechos de aprovechamiento provisionales de aguas subterráneas con cargo a recarga artificial". Disponible en: http://www.dga.cl/orientacionalpublico/guias/ Guias\%20para\%20presentacion\%20de\%20solicitudes/Guia_para_presentacion_solicitudes_DAP_con_cargo_a_Recarga_Artificial_de_Acuiferos $\% 20$ 2016.pdf [visitado el 28.12.2016].

El Mercurio (2018): “Depósitos subterráneos pueden almacenar 600 mil veces más agua que los embalses". Disponible en: http://www.economiaynegocios. $\mathrm{cl} /$ noticias/noticias.asp?id=477469 [visitado el 12.06.2018].

Embid Irujo, Antonio (2008): "La estructura del Estado y la administración hidráulica", en: AA. VV., El derecho de aguas en Brasil y España. Un estudio de derecho comparado (Cizur Menor, Aranzadi).

(2009): "Informe de España", en: Embid, Antonio (Director), Gestión del agua y descentralización política (Cizur Menor, Aranzadi), pp. 247-285.

FERNÁNDEZ ESCALANTE, Enrique (2010): La gestión de la recarga artificial de acuíferos en el marco del desarrollo sostenible (Madrid, DINA-MAR).

Fernández-Escalante, Enrique, y San Sebastián, Jon (2017): "La recarga gestionada en el Acuífero Los Arenales, Castilla y León, España". Disponible en: www.diariodemallorca.es/mallorca/2017/12/01/govern-proyecta-recargaracuiferos-agua.1268562.html [visitado el 12.01.2017].

Gobierno Regional de Coquimbo (2015): "Plan estratégico para enfrentar la escasez hídrica. 2015-2025. Región de Coquimbo". Disponible en: http:// onemi.gorecoquimbo.gob.cl/publico/Plan_Estratégico_Escasez_Hídrica_ RdeCoquimbo_2015-2025_OK.pdf [visitado el 20.10.2016].

Gobierno Regional de Valparaíso (2015): "Estrategia regional de innovación. Región de Valparaíso". Disponible en: http://www.gorevalparaiso.cl/ERI_ Region_de_Valparaiso.pdf [visitado el 20.10.2016].

Gobierno de ChILE (2012): Chile cuida su agua. Estrategia Nacional de Recursos Hídricos 2012-2025 (Santiago, Autoeditado).

Ministerio de Agricultura, Alimentación y Medioambiente (s/d): "Libro Blanco del Agua". Disponible en: http://www.magrama.gob.es/es/agua/temas/ planificacion-hidrologica/libro-blanco-del-agua/ [visitado el 20.10.2016].

Murillo Díaz, J. M. (2002): "Uso conjunto y recarga artificial de acuíferos. Su aplicación a Andalucía y en particular a la provincia de Jaén". Disponible en: http://aguas.igme.es/igme/publica/lib108/pdf/lib108/in_n5e.pdf [visitado el 14.12.2017]. 
National Water Commission (2009): "Managed aquifer recharge. An introduction". Disponible en: https://recharge.iah.org/files/2016/11/MAR_IntroWaterlines-2009.pdf [visitado el 14.12.2017].

(2011 a): "Feasibility of managed aquifer recharge for agriculture", en: Waterlines Report Series ( $\left.N^{\circ} 45\right)$, pp. 1-101.

(2011 b): "Robust policy design for managed aquifer recharge", en: Waterlines Report Series (№ 38), pp. 1-38.

Rivera Bravo, Daniela (2015): "Diagnóstico jurídico de las aguas subterráneas", en: Revista lus et Praxis (Vol. 21, № 2), pp. 225-266.

Rojas Calderón, Christian (2016): La distribución de las aguas. Ordenación y servicio público en la administración hídrica y en las juntas de vigilancia de ríos (Santiago, Thomson Reuters).

Sadoff, Claudia, y Müller, Mike (2010): "La gestión del agua, la seguridad hídrica y la adaptación al cambio climático", en: TEC Backgrouns Papers No 14, Global Water Partnerships. Disponible en: http://www.gwp.org/Global/ToolBox/Publications/Backgroundpapers/ WaterManagementWaterSecurityandClimateChangeAdaptation. EarlyImpactsandEssentialResponses(2009)Spanish.pdf [visitado el 2.03.2015].

Sarmiento Ramírez-Escudero, Daniel (2008): El soft law administrativo. Un estudio de los efectos jurídicos de las normas no vinculantes de la Administración (Cizur Menor, Thomson- Civitas).

SAstre BeCeiro, Mónica (2009): "Aspectos jurídicos de la recarga artificial de acuíferos: regulación actual y retos", en: Boletín Geológico y Minero (Ministerio de Ciencia e Innovación - Instituto Geológico y Minero de España) (Vol. $\left.120, N^{\circ} 2\right)$, pp. 279-288.

Tribunal de Justicia de la Unión Europea (en línea): "Sentencia dictada en causa rol C-403-2011". Disponible en: http://curia.europa.eu/juris/document/ document.jsf?text $=\&$ docid $=128021$ \&pagelndex $=0 \&$ doclang $=e s \&$ mode $=$ re $q \& d i r=\& o c c=$ first $\&$ part $=1 \& c i d=3598949$ [visitado el 14.12.2017]. 
